\title{
La vida del gaucho de la pampa argentina desde una crónica martiana. Estudios y aproximaciones
} The Life of the Gaucho of the Argentinean Pampa in a Chronic by José Martís. Approach and Proposal.

\section{A vida do gaucho do pampa Argentina a partir de uma crônica martiana. Proposta e abordagens}

Yisel Bernardes-Martínez

Centro de Estudios Martianos

Cuba

Recibido: 25/9/2015 Aceptado: 30/10/2015 / http://dx.doi.org/10.15359/tdna.32-59.2

\section{Resumen}

En la crónica titulada "La pampa", publicada en el diario mexicano El Partido Liberal el 19 de diciembre de 1889, la cual también fue publicada en El Sudamericano, de Buenos Aires, el 20 de mayo de 1890, Martí recrea la vida del gaucho argentino en su hábitat. La escritura martiana nos dibuja, con imágenes salidas de una realidad descarnada, natural y libre, la dura existencia del gaucho. La visión martiana nos brinda una idea clara de las luchas y nostalgias del gaucho $y$, en particular, brinda el contrapunto entre la imagen pintoresca del llanero romántico y

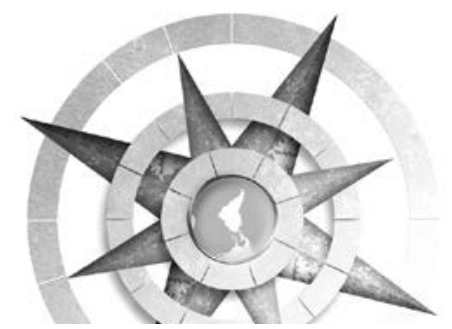

la realidad cruda que enfrenta. Este artículo analiza estos aspectos.

Palabras clave: José Martí, literatura latinoamericana, pensamiento latinoamericano, gaucho, Argentina.

\section{Abstract}

In the article entitled "La pampa," published in the Mexican newspaper El Partido Liberal on December 19, 1889, and in El Sudamericano in Buenos Aires on May 20, 1890, José Martí recreates the life of an Argentinean gaucho in his natural habitat. The Martinian text draws us a picture, with images taken from not only a grim, but a natural and free, reality, of the hard existence of the gaucho. It gives the reader a clear idea of the struggles and nostalgia faced by the gaucho and, in particular, contrasts the picturesque image of the romantic plainsman with the hard reality he faces. This article analyzes these aspects. 
Keywords: José Martí, Latin America Literature, Latin American Thinking, gaucho, Argentina

\section{Resumo}

No artigo intitulado "O pampa", publicado no jornal mexicano El Partido Liberal em 19 de Dezembro de 1889, e na Sudamericano, em Buenos Aires em 20 de Maio de 1890, José Martí recria a vida de um gaúcho argentino em seu habitat natural. O texto nos desenha um retrato, com imagens extraídas do uma realidade triste, natural e livre, da existência dura do gaúcho. Ele dá ao leitor uma noção clara das lutas e saudades vivenciadas pelo gaúcho e, em particular contrasta a imagem pitoresca do cowboy romântico com a dura realidade que enfrentei. Este artigo analisa esses aspectos.

Palavras chave: José Martí, literatura latino-americana, pensamento latino-americano, gaucho, Argentina.

En la crónica titulada "La pampa", publicada en el diario mexicano El Partido Liberal el 19 de diciembre de 1889, la cual también fue publicado en El Sudamericano, de Buenos Aires, el 20 de mayo de 1890, Martí recrea la vida del gaucho argentino en su hábitat, y utiliza para ello la presentación de un libro nuevo del escritor francés Alfred Ebelot (1890). La escritura martiana nos dibuja, con imágenes salidas de una realidad descarnada, natural y libre, la dura existencia del gaucho.

Comienza su crónica describiéndonos la portada del libro, que en sí misma es una imagen de vida, para decirnos que: "El gaucho viene, a caballo tendido, por la llanura, mirando atrás de sí, como quien desconfía"(Martí, 1963: p 367). . Con pocas palabras nos muestra a este vaquero pampeano, que corre por su amplia llanura como jinete hábil e intrépido, que se gana la vida vigilando al ganado o comerciando ilegalmente con caballos o reses en la frontera brasileña. De esta manera sobrevive en la pampa argentina, y en la cual, hasta la segunda mitad del siglo XIX, se impuso con un modo de vida independiente y duro montado a lomo de su caballo -imagen clásica de los llaneros, llamados "hombres-caballos", pues estos últimos son la herramienta insustituible para el manejo del ganado-.

De ahí que "Su caballo batallador, enhiestas las orejas y vigilantes los ojos, saca del pecho membrudo, en un arranque de galope, las manos de cañas afiladas" (1963: pág. 365). Con su actitud expresa los deseos exaltados y los instintos; ${ }^{2}$ nos

1 En lo sucesivo, OC. (N. de la E.).

2 Para un estudio más profundo sobre lo que simboliza el caballo en la mitología griega y

24 La vida del gaucho de la pampa argentina desde una crónica martiana. Estudios y aproximaciones Yisel Bernardes-Martínez

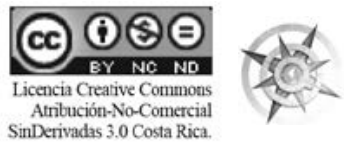


recuerda lo mitológico cuando se desplazaban por el cielo, de un elemento o mundo al otro; los dioses y héroes, pues, en el contenido de sobrevivencia que encierra la existencia de estos llaneros, puede verse al gaucho-héroe empeñado en no desaparecer. También en la mitología indoeuropea el caballo tiene un lugar especial por su utilidad en la economía y las migraciones de los antiguos pobladores. ${ }^{3}$

A causa de su velocidad, los equinos pueden significar el viento y las espumas marinas, también el fuego y la luz. Esto pudiera explicar por qué el caballo del gaucho logra intuir el peligro y/o colocarse en posición de lucha, y rápido, tendido, sin desbocarse, galopar violentamente; así como, en un arranque, en una fiesta a caballo, sacar del pecho las cañas afiladas que se arrojan los gauchos como escaramuzas que se hacen entre ellos, y que luego se resguardan con las adargas. Hay un momento en el retrato en el que no sabemos quién saca del pecho membrudo las cañas, si el jinete o el caballo. Martí

que sirve de base para el análisis de esta imagen en la obra martiana, se puede consultar a Paul Diel en Le Symbolisme dans la Mythologie grecque, París, 1952.

3 Véase en Árbol del mundo. Diccionario de imágenes, símbolos y términos mitológicos, La Habana, Casa de las Américas-UNEAC, el análisis sobre la importancia y función del caballo en muchos sistemas mitológicos de Eurasia. los une dialécticamente: no es posible que exista uno sin el otro, porque el caballo es el símbolo del vehículo corporal y el gaucho es el espíritu.

Así, este conjunto veloz hace que "El poncho, cogido sobre la arzonera, flota al aire, dorado y azul" (pág. 365). El abrigo, cogido sobre el arzón, parte de la cabalgadura, puede simbolizarnos la esfera animal en el ser humano, las fuerzas de los instintos y también lo dominado en la esfera inferior. Recordemos que en la India la cabalgadura se interpreta como vahana (materialización $)^{4}$ de un acto del que se sale airoso. Y nuestro gaucho se realiza cuando montado en su caballo, ondea al aire su poncho dorado y azul.

Otro elemento de la naturaleza, esencial para este hombre de la llanura, es el aire. El aire para el gaucho nómada es el espacio, ámbito de movimiento y de producción de procesos vitales. La luz, el vuelo, la ligereza, así como el perfume y el olor de la propia naturaleza, son elementos en conexión con la imagen del aire. El aire puede ser una especie de materia superada,

4 Debe tenerse en cuenta que la mayor parte de las figuras mitológicas, además de sus atributos instrumentales, poseen una cabalgadura determinada. Recordemos que en un relieve de coraza, representada en una estatua de mármol romana, Minerva está de pie sobre una loba. Para un análisis más pormenorizado, consúltese a Heinrich Zimmer en Mythes et Symboles dans l'Art et la civilisation de l'Inde, París, 1951. 
adelgazada, ${ }^{5}$ como la materia misma de la libertad primitiva del gaucho, que lleva en su poncho los colores del cielo.

El abrigo combina el azul con el dorado, imagen de la vivificación solar del hombre que vive y cobra fuerza en un entorno natural, donde nace el gaucho que "a horcajadas; con la rodilla guía a su compañero, más que con la rienda" (p. 367). Aquí se nos muestra a un gaucho dominador, cuyo espíritu prevalece sobre la cabalgadura y las riendas, pues su rodilla, su contacto humano, posee más fuerza para guiar que cualquier otro objeto. Esto no es posible sino a través de una larga técnica de aprendizaje. Podemos verla, en su aspecto histórico, como un real esfuerzo por crear un tipo humano -el gauchosuperior en su capacidad de resistencia para sobrevivir hasta donde pudo, y hacerlo con un espíritu, en ocasiones brutal y siempre pintoresco; de ahí que sea apreciados como una figura heroica en el folclore, la música y la literatura sudamericanas.

5 Dice Gaston Bachelard que, para uno de sus más claros adoradores, Nietzsche, la marca verdadera de lo aéreo se funda en la dinámica de la desmaterialización. Para Nietzsche, el aire debía ser frío y agresivo, aire de las cumbres. Léase, de Gaston Bachelard, L'Air et les Songes, París, 1943.
Su vestimenta ayuda a corroborar lo anterior: "trae calzones azules y camisa blanca; al cuello lleva un pañuelo rojo; el sombrerete de ala floja va bien sujeto, por el barboquejo, a la cara lampiña"(p. 367). Obsérvese cómo Martí pone esta portada en movimiento, dotándola de un carácter cinematográfico en que podemos ver al gaucho con su indumentaria típica, con un sombrero plano de ala, pantalones holgados sobre las botas, un poncho de lana y un pañuelo.

Si nos remontáramos a la alquimia medieval, ${ }^{6}$ se podría establecer asociaciones entre los colores que lleva el gaucho consigo y su contenido moral. Él trae tonos ascendentes, progresivos como la camisa de blanco y el pañuelo rojo. El primero nos trae a nuestro nómada en estado natural, de mostración y alegría; y, el segundo lo matiza con la pasión por conquistar y vencer, el amor y el dolor, la sangre, las heridas, compensados con el azul y el dorado como símbolos del factor celeste y terrestre natural. Tal vez la vestimenta colorida del gaucho nos asome a los matices contradictorios de su personalidad.

Martí, después de presentado el gaucho pintoresco, nos lo ubica en un

6 Para un estudio más profundo sobre este contenido, puede consultarse, de P. V. Piobb, Chef universelle des Sciences secrètes, París, 1950.
26 La vida del gaucho de la pampa argentina desde una crónica martiana. Estudios y aproximaciones Yisel Bernardes-Martínez
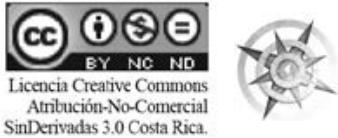
espacio que no permite realizar muchas inferencias, porque en las "páginas que convidan a leer [...] se ve, en su ternura y ferocidad, la vida de la pampa, de la planicie imponente y melancólica" (p. 367). Se nos anticipa ese contrapunto entre rebelión y melancolía, que será permanente en toda la crónica. La ternura vinculada con ese entorno natural de las verdes llanuras meridionales de Sudamérica, donde el hombre puede encontrar sus raíces y anda casi libre; la ferocidad en esa lucha que impone la pampa ganadera, inmenso escenario para esa actividad, un mundo sin cercas, cuyos únicos límites quedan determinados por las corrientes de agua, donde el abigeato o cuatrerismo es una práctica habitual.

La pampa imponente en su grandeza desarbolada y melancólica, en su soledad desértica que la hace parecer una región intermedia entre el cosmos y el caos, ${ }^{7}$ porque también "Allí

7 El caos, apreciado en su vínculo especial con la naturaleza, y sobre todo con el elemento acuático: agua, océano del mundo, la infinitud en el tiempo y el espacio, la separación hasta la vacuidad, o, a la inversa, la mezcla de todos los elementos como estado amorfo de la materia que no solo excluye la objetualidad, sino también la existencia en forma separada de los elementos y los parámetros principales, la ausencia de ordenamiento y de la esfera de lo predecible. Tal vez el principal rasgo del caos sea su función de vientre donde es engendrado el mundo, o sea, la existencia en él de cierta energía que conduce al engendramiento. Para la vida [es] intensa bajo el techo del cielo, con el recado por montura y posada" (p. 367). El gaucho, no posee más que su caballo y su chinchorro, sus frijoles como dieta casi exclusiva, y, solo si hay "cuereo" de reses, algo de carne. Su vida nos muestra un ámbito que acepta todas las posibilidades de sobrevivencia, y a la vez resulta un espacio, un lugar donde se definen formas y construcciones de un mundo: "la pulpería, el club del desierto, con sus velorios y sus rimas, sus carreros y sus cantos, su ginebra y su conversación, su alboroto y su comercio" (p. 367) va ofreciendo un cosmos que se concibe sobre la base de un patrón humano en el cual la realidad invisible o espiritual se corresponde con la física, pues la esencia de todos los fenómenos es, en último término, rítmica vibratoria. La naturaleza íntima de los fenómenos es directamente perceptible en la polirrítmica conciencia humana.

Ningún otro horizonte, como no fuera el de los llanos, se le avizora al gaucho, y esto encuentra relación con el contenido de su actividad, pues poco es el trabajo e intenso solo en algunos momentos del año. Al llegar la temporada de la

mayor información, léase, de H. P. Blavatsky, La doctrina secreta de los símbolos, Barcelona, 1925, y, de Leo Frobenius, Histoire de la Civilization africaine, París, 1952.

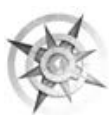


inundación, el ganado se refugia espontáneamente, concentrándose en aquellos lugares donde, según su instinto, no se anegaría. Y durante ese período, el gaucho no puede resolver mucho. No obstante, hace su esfuerzo, como modo de sobrevivencia brutal y a modo de diversión: "Allí, en los yerbales profundos, la 'boleada', la caza a caballo, con el arma de las bolas; el 'baqueo', siguiendo la pista del indio temible por la piedra y el agua." (p. 367)

Las armas que utilizaban en la captura de caballos salvajes y de otras reses, con frecuencia para hacerse de su piel, eran el lazo, una cuerda con un nudo corredizo en uno de sus extremos y las boleadoras, un tipo de honda formada por varias bolas unidas mediante una soga fuerte, que se lanzaba para inmovilizar las patas de la presa. La fabricación del cuero también era una fuente adicional de ingresos para los gauchos, y muchos de ellos eran también artesanos nómadas.

El baqueo como acto, golpe de éxito, batacazo en que se triunfa a caballo tras la captura de un indio "temible". He aquí la imagen del indio reiterada en la crónica, apreciada detrás de una historia. Y una vez más una lección martiana al estudiar la relación de lo histórico con lo ético, al regalarnos una representación permanente y nítida del indio en el texto. Su lucha, su astucia, incorporada desde que nace, trasmitida de generación en generación para sobrevivir, y la visión preclara del escritor que despoja esa imagen del concepto ingenuo, puritano con que, en ocasiones, se le ve desde el inicio de su historia hasta el final.

El indio "temible por la piedra y el agua", dos elementos esenciales que utiliza como armas para despistar y huir del gaucho, que a caballo le resulta un enorme obstáculo.

La relación del indio con la piedra y el agua nos enfrenta con un universo plural, pues lo esencial es la captación, la identificación cultural de los símbolos piedra y agua así como su intelección, no su "interpretación" restringida a la luz de una situación dada.

Esa piedra que ayuda al indio cuando es perseguido por el gaucho es un elemento cultural sobresaliente de la cultura megalítica. Como residencia de las almas, los círculos culturales de piedras expresaban lo esencial de lo humano, brotando del inconsciente en forma de anhelo constructor y configurador. Es la persistencia de esas formas primarias de la vida, e intelección del mundo, lo

28 La vida del gaucho de la pampa argentina desde una crónica martiana. Estudios y aproximaciones Yisel Bernardes-Martínez

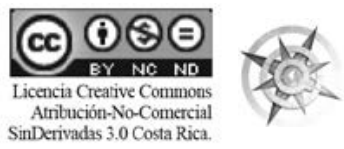


que imprimió huellas indelebles en el alma del hombre.

Hasta nuestros días, la piedra ${ }^{8}$ puede verse como un símbolo del ser, de la cohesión y la conformidad consigo mismo. La unidad y la fuerza unida al agua, ${ }^{9}$ como amparo del indio, conforman dos elementos naturales poderosos. En las más diversas mitologías, el agua es originariamente el estado inicial de todo lo existente. Es el medio, el agente y el principio de la concepción y la génesis universal. En general, en la India se considera a este elemento como el mantenedor de la vida que circula a través de toda la naturaleza en forma de lluvia, savia, leche, sangre.

Una ampliación secundaria de este simbolismo se halla en la asimilación del agua y la sabiduría intuitiva presentes en el espíritu indígena para escapar de sus perseguidores.

Por otra parte, el agua es el elemento que mejor aparece como transitorio, entre el fuego y el aire de un lado

8 Para ahondar en el estudio de la piedra como símbolo, véase, de Marius Schneider, El origen musical de los animales-símbolos en la mitología y la escultura antiguas, Barcelona, 1946, así como, del mismo autor, La danza de espadas y la tarantela, Barcelona, 1948.

9 El agua es un símbolo de referencia básica, véase, entre muchos otros estudiosos, a Gaston Bachelard en L'Eau et les Rêves, París, 1942; también a Louis Chochod en Occultisme et Magie en Extrême-Orient, París, 1945. -etéreos- y la solidez de la tierra. El agua sobresale en hacer el bien. Si se le opone un dique, esta se detiene; si se le abre camino, discurre por él. He aquí por qué se dice que no lucha. Y, sin embargo, nada le iguala en romper lo fuerte y lo duro.

El agua simboliza la vida terrestre, la vida natural, nunca la vida metafísica. El gaucho, imagen fuerte de vida, tiene estos rivales naturales y al indio que persigue. Este, de condición semejante, a la de él, labrado de una naturaleza similar, es nómada, pobre, mestizo y en sobrevivencia permanente. Sus enemigos esenciales son los de "la pelea de la 'partida' de soldados" cuando el gaucho malo se alza contra la justicia y "se quita de encima las balas a punta de cuchi1lo". (p. 367)

El gaucho malo se enfrenta a los soldados con la ayuda del cuchillo, arma y herramienta inmediata, asociada con las ideas de ferocidad, venganza y muerte, pero también a las de sacrificio, porque "el indio jinete" -como le llama Martí, y ahí lo iguala al otro indio- "cría a sus hijos para el exterminio del blanco invasor, y la tropilla que le rinde la vida y la hacienda, o lo echa sobre sus 'toldos' a balazos". (p. 367)
La vida del gaucho de la pampa argentina desde una crónica martiana. Estudios y aproximaciones Yisel Bernardes-Martinez 
La corta dimensión de la hoja del cuchillo representa analógicamente lo primigenio del instinto que lo maneja, como la altura de la espada -inversamente- expone la altura espiritual de su poseedor. Ahí encontramos el primitivismo en esa imagen de resolver conflictos y defender derechos a punta de cuchillo, pero también la lucha como camino y defensa, no debe olvidarse que los gauchos fueron heroicos combatientes en la historia de Argentina, sobre todo, durante las guerras de emancipación.

Martí con su aliento poético, pero sin desligarse jamás de lo histórico, nos habla de una vida primitiva y heroica que va desapareciendo con la arremetida imponente del desarrollo, pues en la segunda mitad del siglo XX, la modernización de la cría de ganado, la llegada de granjeros europeos a Sudamérica y la parcelación de las pampas marcan el fin de los gauchos.

Sin embargo, nuestro escritor no deja de alabar su resistencia y se asombra de que aún

En setecientas leguas de soledad, a las puertas de las ciudades universitarias, vive aún, con la tradición confusa de lo indio y lo español, una casta natural y fiera, nacida de los castillos ${ }^{10}$ y la indiada, hecha al caballo y a la sangre. (p. 368)

Este gaucho logró desafiar durante mucho tiempo la vida de la urbe, espacio casi impenetrable. Recordemos que el hecho de fundar una ciudad $^{11}$ está en estrecha conexión con la constitución de una doctrina, y, por ello, es un símbolo de esos preceptos establecidos y de la sociedad dispuesta a defenderla.

En la antigüedad, los muros de la ciudad tenían carácter mágico, pues eran interpretados como símbolos de la limitación dogmática, y el gaucho, sin importarle estas cuestiones, logró imponer un estilo de vida contrario a las costumbres citadinas, trasgresor en los mismos ojos de "las ciudades universitarias" para, finalmente, quedar él en la literatura e historia de su país.

La resistencia del gaucho puede explicarse en su origen y trayecto existencial; en su mayoría eran nómadas mestizos, mezcla indígena y española, fuertes en su identidad, vista y conformada, a través de un gaucho heroico, cruel, conciso, áspero,

10 En El Partido Liberal: "castillas".

11 Véase, de Renè Guènon, Il Re del Mondo, Roma, 1950. También puede consultarse a Ramiro Pinedo en El simbolismo en la escultura medieval española, Madrid, 1930.

30 La vida del gaucho de la pampa argentina desde una crónica martiana. Estudios y aproximaciones Yisel Bernardes-Martínez

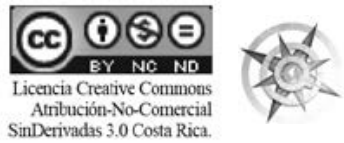


valiente, que vive en un universo violento y sintético, que se hace "al caballo y a la sangre" y así anda como un dios del sol en un carro de combate tirado por caballos, en pareja como en los gemelos, en forma de pareja con uno blanco y otro negro, pues simbolizan vida y muerte. ${ }^{12}$

De esta manera, el gaucho transita un camino complejo en el cual el par de categorías vida/muerte es un valor trascendente. En los rodios la vista de un caballo se consideraba presagio de guerra. Soñar con un caballo blanco en Alemania o en Inglaterra se consideraba presagio de muerte. Pero esa unión de caballo y sangre como síntesis de un modo de vida, nos asoma a un gaucho que ha transitado por todas las pruebas, ensangrentado por todos los sacrificios, supremamente tanto viril como dominador, y quien, logrando trascender su circunstancia, es acreedor de la gloria. Por otra parte, la sangre no siempre deviene completamente en el aspecto brutal, destructor, de muerte, también las culturas arcaicas la consideraron como un acto de fecundación, tanto por el valor del sacrificio como por la

12 Resulta interesante anotar que el gran mito y símbolo del Géminis, manifestado en los gemelos, en los animales bicéfalos, en las figuras antropomorfas de cuatro ojos y cuatro brazos, etc., aparece también en los caballos, en forma de pareja con un caballo blanco y otro negro para simbolizar vida y muerte. analogía sangre-semilla, unida a los instintos de vida.

Dice Martí que Alfred Ebelot "pinta la pampa que se va", en la que el gaucho "canta de noche" y "anda vivo, con la guitarra al hombro, por el desierto americano", (p. 368) porque también el universo de este indio nómada, a la vez que descarnado, resulta familiar y musical con sus fiestas al aire, las cuales pueden terminar a cuchilladas por una mujer $\mathrm{u}$ otro asunto que lastime la hombría del gaucho, sus pulperías, sus velorios, el mate bebido al alba en cuclillas antes de la carrera que emprenderá en el día. Todas son imágenes que nos dibujan la pampa y su gaucho, y que Martí quiere que se lean porque es parte de nuestra gesta homérica, de lo autóctono americano. Por ello, esta crónica se convierte en un homenaje a un gaucho que resumido en el caballo como su símbolo "el tigre mismo no logra acobardar". (p. 368)

Ese tigre, que en las ideas mitopoéticas aparece con frecuencia como el rey de los animales y el señor del bosque, también como espíritu de las montañas y las cuevas... El tigre que inspiró ritos especiales vinculados con la idea de su enorme fuerza vital, y que los distintos clanes entre las tribus de la India identificaban 
con sus hombres más valientes: "hombre-tigre", designación del heroísmo elevado. ${ }^{13}$

El gaucho vence con su caballo heroico a este tigre, y Martí cuando presenta el libro sobre la pampa nos lleva de la mano, apurados para ver con nuestros propios ojos los matices contradictorios de la personalidad del gaucho en su vida natural y libre, sin lecciones prehechas, sin falso adoctrinamiento, y critica algunas apreciaciones del autor que no tiene, sería muy difícil, la comprensión dialéctica martiana que se duele cuando Ebelot:

no ve más que barbarie primitiva y necesidad feroz de sangre en el indio descendiente de generaciones oteadas y acuchilladas por el blanco, que congrega a su prole, frente al cautivo blanco atado, a que con sus manos indias cumpla la justicia que manda cumplir la tierra de sus padres, manchada por el invasor. A crudeza animal, e insistencia de la fiera en la composición humana, atribuye la familiaridad, que le parece gusto, del gaucho con la sangre, sin notar que esta es consecuencia de la vida carnicera del gaucho, que se

13 Para un estudio más profundo de este símbolo, léase a Z. P. Sokolova en El culto a los animales en las religiones, Madrid, 1972 y a Eliade Mircea en su Tratado de historia de las religiones, Madrid, 1954. ve, en las comunidades civilizadas, en los mataderos ${ }^{14}$ de reses, casado con el cuchillo." (p. 370).

Desconoce emocionalmente el escritor francés, el valor de los orígenes, la historia de injusticias, el camino de sobrevivencia de un nómada despojado de sus elementales derechos y en cuya acción se evidencia una lucha o victoria que en el plano material tiene su correspondencia con el dominio del espíritu, a saber, la dureza del gaucho para resistir, la cual resulta trascendente porque es la que permite la permanencia de su principio espiritual dominador.

Una propiedad constante e inalienable del camino del gaucho es la dificultad. Su recorrido está construido de acuerdo con una línea de complejidad y peligro siempre crecientes que lo amenazan; por eso, la superación del camino es una hazaña, un acto de devoción del nómada; de ahí su gozo primitivo cuando vence a una fiera o a otro hombre. Esta imagen dinámica del camino, ligada a un riesgo máximo, responde al carácter de no poseer un punto, un espacio límite como una casa, un lugar de refugio, descanso seguro, y eso explica que para él tenga significación y valor lo que está vinculado a un esfuerzo extremo, a una

14 En El Partido Liberal: "Matadores".

32 La vida del gaucho de la pampa argentina desde una crónica martiana. Estudios y aproximaciones 
situación, que da lugar al proceso de formación del gaucho.

Martí no ignora la relación entre comportamiento-realidad. El camino de este indio-jinete está lleno de indeterminaciones: la bifurcación del camino, la encrucijada, que presagia el peligro de obstáculos inesperados, como el río desbordado, la serpiente, la fiera carnicera, el gaucho malo, el blanco invasor, las cuales entrañan una amenaza permanente para la propia realidad de este llanero pampeano. Por ello se explica que:

el valor es una nobleza a que busca salida el hombre, siempre amigo de lucir la habilidad y la bravura; colorada es la sangre del hombre, como la del toro; al toro, que no ofende, se le mata, y ¿o no se ha de matar al que ofende la vanidad y el puntillo salvaje? (p. 370)

La escritura martiana nos lleva hacia una lógica de una raíz natural, emanada de la sencillez compleja que no abandona a los buenos, entiéndase como los inteligentes de fuerza intrínseca para comprender lo necesariamente humano, desde dimensiones que toquen la emoción, mediante una capacidad empática, difícil de lograr en ocasiones.
De ahí, que Martí aprecie el valor como salida humana ante conflictos y establezca una analogía que iguala la sangre del hombre con la del toro, porque es sangre animal, y al toro inocente lo mata el hombre, y puede hacerlo, de manera oficial, "el hombre civilizado", quien quiere divertirse con el espectáculo y creó academias para enseñar a ser torero. No solo el gaucho le impone un destino fatal al toro, sino los hombres cultos que ponen en el ruedo a un animal que nunca vuelve al corral. La tauromaquia nació en la civilización europea. Martí cuestiona retóricamente el porqué este gaucho salvaje y abandonado en su vida errante, no puede matar cuando le ofenden su vanidad. Hay una ley de analogía universal que siempre respeta nuestro escritor.

¿A qué buscar en particularidades locales lo que es de la naturaleza común de cuantos pueblos empiezan a vivir? Tiene el gaucho argentino velorios, como el canario campesino y el vulgo irlandés. En la pampa visten de fiesta al muertecito, con sus vestidos mejores, y en Colombia le ponen zapatos dorados, porque es de espinas el camino del cielo, y no quiere la madre, ¡no quiere! "que se le entunen" al hijo los pies. Batea su carne el cazador pampero, lo mismo que el indio del Norte. ( $\mathrm{p}$. 370-371)

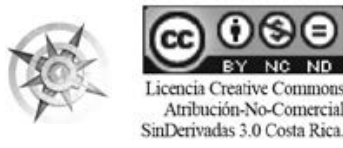

La vida del gaucho de la pampa argentina desde una crónica martiana. Estudios y aproximaciones Yisel Bernardes-Martínez 
Puede sentirse en la crónica martiana un entendimiento hacia la naturaleza común de los pueblos y los hombres desde los inicios de la existencia, la cual se ve la falta de ordenamiento, la separación del camino de lo predecible, cierta aleatoriedad que, por momentos, excluye la categoría de causalidad, pero en la que se avizora un acercamiento inicial hacia la esfera de lo cultural, de lo humano, apreciada en los velorios, en la manera de vestir a sus muertos, en el dolor espiritual por la pérdida, así como en la protección y belleza de sus ropas para que vayan con dignidad sus seres más preciados a un lugar desconocido.

También la manera de sentir y su proyección se relaciona con la pobreza, así vemos la imagen de un funeral en que:

Dentro bailan [...] los pares de novios, que se persignan al pasar frente a la silla donde está sentado el niño muerto, sobre un pie de cajones vacíos, con treinta y seis velas de sebo alrededor, ${ }^{15} \mathrm{y}$ a un lado el gaucho viejo, de canas por el hombro, rasgueando la guitarra, y al otro lado la madre, con las manos cruzadas sobre las rodillas y los ojos secos. Hay pocas fiestas en la soledad, y el pulpero le toma en alquiler su muertecito al gaucho pobre, que sí se lo alquila para que el ángel tenga velas y vaya al cielo como se debe, con canto y velorio, ya que la suerte negra tiene en el hilo vivo el poncho de sus padres. (p. 372)

La pobreza, junto a la vida errante e indócil del gaucho, es una imagen completa en la crónica, La fiesta del velorio triste, donde podemos imaginar la expresión del gaucho viejo que ha perdido a su hijo. Su rostro, curtido por la dura vida, reponiéndose de su tristeza para negociar con el pulpero un velorio digno. El niño muerto, yace sobre unos cajones, la postura de la madre, las velas y los cantos nos dan el color del pauperismo; su mirada, sus vestidos, el espíritu resignado ante la pérdida y el desamparo permanente del pobre.

En otro ámbito, tenemos el modo de divertirse del gaucho y su manera ruda de solucionar conflictos. Ambas están relacionadas con la idea anterior, para ir a lo más hondo, que puede ser lo esencial. Martí se refiere a un personaje gauchesco del libro y dice que:

El Gato Moro juró guerra a los jueces de paz, y mató cinco de una función de cuchillo; pero los jueces de paz le quitaron al Gato Moro su caballo querido, 'su

15 En El Partido Liberal: "al rededor".

34 La vida del gaucho de la pampa argentina desde una crónica martiana. Estudios y aproximaciones Yisel Bernardes-Martínez

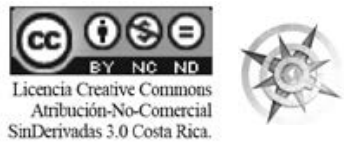


crédito', o su recado de plata, o su 'china' amorosa. (p. 371)

Aparecen aquí las relaciones entre la inteligencia y los aspectos tanto volitivos como sentimentales de la conducta humana a modo de condiciones activas que modelan el carácter. La ferocidad del Gato Moro está antecedida por el despojo de sus pertenencias esenciales, que son pocas, para sobrevivir. De ahí que la crónica también sea un llamado para que escuchemos y estemos dispuestos, a entender otras culturas o modos de sobrevivencia que tienen que ver con nuestros orígenes, porque "El hombre es uno, y el orden y la entidad son las leyes sanas e irrefutables de la naturaleza”. (p. 372)

Detrás del aspecto de la crueldad, de la bestialidad con que puede a su hora actuar un gaucho, porque "Los gauchos, a la verdad, 'son gentes buenas cuando se sabe por dónde tomarlos"' (p. 372), hallamos las heridas físicas y espirituales como huellas permanentes de la pobreza, la injusticia y el abandono. También su sentido de vida, limitado en extremo, y su contenido de trabajo, porque el hombre es, primariamente, lo que hace. Sus paisajes solitarios y fijos, desolados y su comida, en fin, la vida del gaucho, conforma una imagen paupérrima la cual trata de animar, de impregnarle vida en soledad, a solo como puede.

Y Martí, que conocemos quien rechazó todo aquello que solo proporciona un saber sin influir inmediatamente en la vida, le hace un homenaje al gaucho que se despide, entendiéndolo en su bregar, en su heró́smo y en su crueldad, porque no lo ve ajeno a nuestra realidad. Todo lo contrario, ve en esa influencia, una modificación y una rememoración de lo trascendente.

\section{Referencias bibliográficas}

Marí, J. (1889, 19 de diceimbre) La Pampa. El Partido Liberal. Ciudad de México: José Vicente Villeda, Editor.

Martí, J. (1890, 20 de mayo) La Pampa. El Sudamericano. Buenos Aires, Argentina: Cía Sud-Americana Eds.

Ebelot, Alfred (1890) La Pampa. Costumbres argentinas. Buenos Aires: Joseph Escary Ed.

Martí, J. (1963-1973) La Pampa. En Obras completas. 